\title{
Clinical Profile, Outcome and Risk Factors for Mortality of Neonates Requiring Mechanical Ventilation at Tertiary Care Centre of Central Gujarat, India
}

\section{Pareshkumar A Thakkar, Himanshu G Pansuriya, Sheela Bharani, Khushboo Kamal Taneja}

Department of Paediatrics, Medical College, Vadodara, Gujarat, India

\author{
Correspondence: \\ Khushboo Kamal Taneja \\ Department of Paediatrics, \\ Medical College, \\ Vadodara, Gujarat, India \\ Email:khushbooktaneja@gmail.com
}

DOI: $10.3126 /$ jnps.v41i1.30630

Submitted on: $2020-08-13$

Accepted on: 2021-02-14

Acknowledgements: None

Funding: Nil

Conflict of Interest: None declared

Permission from IRB: Yes

To cite this article: Thakkar PA, Pansuriya HG, Bharani S, Taneja KK. Clinical Profile, Outcome And Risk Factors For Mortality Of Neonates Requiring Mechanical Ventilation At Tertiary Care Centre Of Central Gujarat, India J Nepal Paediatr Soc. 2021;41(1): 29-34.

\section{ABSTRACT}

Introduction: Mechanical ventilation is an important factor contributing to the reduced neonatal mortality in NICU. However, many ventilated babies are left with detrimental sequelae. This study was undertaken to know the prognostic predictors and survival outcome in the ventilated neonates. We assessed the clinical profile, outcome of mechanical ventilation and analysed the risk factors for mortality and complications resulting from mechanical ventilation.

Methods: A prospective study was conducted at the NICU of a tertiary care hospital in India. The study period was from May 2015 to April 2016. Neonates who underwent mechanical ventilation and met the inclusion criteria were enrolled in the study. Their demographic profile, outcomes and risk factors were documented and analysed using appropriate statistical methods.

Results: 285 neonates required mechanical ventilation during the study period. Among them, 190 were included in the study. Overall mortality was 99 out of the 190 enrolled (52\%). The most common indications for mechanical ventilation were Respiratory Distress Syndrome (RDS), Meconium Aspiration Syndrome (MAS) and apnea. Risk factors contributing significantly to higher mortality of ventilated neonates were very low birth weight (VLBW), gestation of less than 32 weeks, shock, ventilatorassociated complications like pneumothorax and pulmonary haemorrhage. In multiple regression analysis, very low birth weight, circulatory disturbances, pneumothorax, pulmonary haemorrhage, and higher initial $\mathrm{FiO}_{2}$ requirement were found to be independent risk factors of mortality.

Conclusions: The commonest indications for mechanical ventilation were RDS and MAS. Significantly higher mortality was seen amongst VLBW, preterm neonates. Co-morbidities like circulatory disturbance, and complications like pneumothorax and pulmonary haemorrhage contributed to adverse outcomes.

Keywords: mechanical ventilation; neonates; outcome

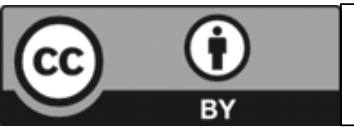

This work is licensed under creative common attribution 3.0 license 


\section{INTRODUCTION}

As per the Sample Registration System (SRS) 2017 report, the present Infant Mortality Rates (IMR) of our country and Gujarat are 37 and 30 per 1000 live births respectively, ${ }^{1}$ against targeted 27/1000 live births under Millennium Development Goals-4, which was to be achieved by $2015,{ }^{2,3}$ despite a plethora of measures taken by the Government with focus on neonatal health.

The improved access to neonatal mechanical ventilation is an important factor contributing to the reduced neonatal mortality in today's age. However, significant number of ventilated babies who survive, do so with detrimental sequelae due to their turbulent NICU stay; due to many economic and infrastructural hurdles in a low-income country like India.

Various Indian studies report a survival rate of $40 \%$ to $60 \%{ }^{4}$ Thus, this study was undertaken with the objectives of studying the clinical profile, outcome of mechanical ventilation in neonates and analysing the risk factors for mortality and complications resulting from mechanical ventilation and their effect on survival.

\section{METHODS}

A prospective, hospital-based study was conducted at the NICU of Kashiben Gordhandas Patel Children Hospital (KGP), Vadodara, Gujarat, India. The study period was from May 2015 to April 2016. The study was commenced following approval from the Institutional Ethical and Scientific Committee. The sample size of 232 was derived by applying formula $\mathrm{N}=4 \times \mathrm{pq} / \mathrm{L}^{2} ; \mathrm{N}=$ sample size; $\mathrm{p}=$ positive factor i.e. proportion, $\mathrm{q}=$ $100-\mathrm{p} ; \mathrm{L}=20 \%$ allowable error, precision, variability.

During the study period of one year, 285 (21.9\%) neonates of total 1299 admissions were mechanically ventilated, of which 232 (17.8\%) neonates fulfilling the inclusion criteria were enrolled after taking a written informed consent from the parents.

Forty-two babies took discharge against medical advice during the study or were ventilated prior to admission, thus they were excluded. Finally, 190 $(14.6 \%)$ cases requiring ventilator support were analysed.

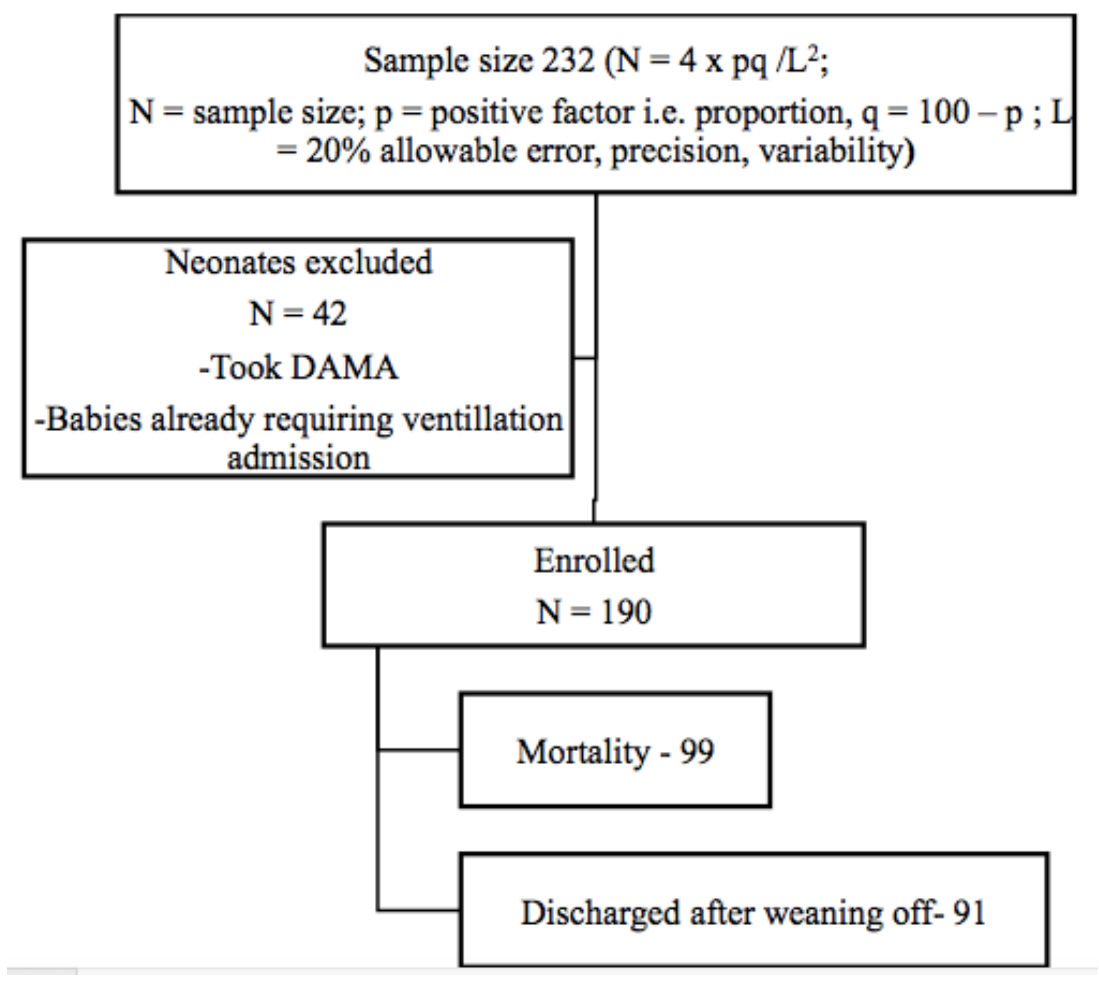

Figure 1. Study flowchart 
Table 1. Demographic variables of the enrolled neonates requiring ventilation

\begin{tabular}{|c|c|c|c|}
\hline $\begin{array}{l}\text { Demographic } \\
\text { variables }\end{array}$ & Distribution & $\begin{array}{l}\text { Number } \\
\text { of cases } \\
(N=190)\end{array}$ & $\begin{array}{c}\text { Percent } \\
\text { of total } \\
\text { Cases } \\
(\%)\end{array}$ \\
\hline Area & Rural & 109 & 57.4 \\
\hline \multirow[t]{2}{*}{ Place of birth } & $\begin{array}{l}\text { KGP Hospital } \\
\text { (Inborn) }\end{array}$ & 13 & 6.8 \\
\hline & Out born & 177 & 93.2 \\
\hline \multirow{3}{*}{$\begin{array}{l}\text { Age on } \\
\text { admission }\end{array}$} & $<24$ hours & 120 & 63.2 \\
\hline & $1-7$ days & 51 & 26.8 \\
\hline & $>7$ days & 19 & 10.0 \\
\hline \multirow[t]{3}{*}{ Gestation } & $<32$ weeks & 32 & 16.8 \\
\hline & $32-36$ weeks & 60 & 31.5 \\
\hline & $>37$ weeks & 98 & 51.5 \\
\hline \multirow[t]{4}{*}{ Birth weight } & $<1000$ grams & 15 & 7.9 \\
\hline & $\begin{array}{l}1000-1500 \\
\text { grams }\end{array}$ & 26 & 13.7 \\
\hline & $\begin{array}{l}1500-2500 \\
\text { grams }\end{array}$ & 83 & 43.7 \\
\hline & $>2500$ grams & 66 & 34.7 \\
\hline Gender & Male & 124 & 65.3 \\
\hline
\end{tabular}

For all included neonates, a thorough history was taken as per a set proforma, then they were examined and gestational age was established by using the expected date of delivery and / or expanded new Ballard score. Neonates presenting with respiratory distress were assessed by Downe or Silverman Anderson score (SAS). A provisional diagnosis was made based on the clinical condition and initial blood gas report, and a decision was taken for mechanical ventilation.

Treatment of ventilator related complications, and other supportive management were undertaken as per standard NICU protocols. Outcome was determined in terms of survival and days of hospitalisation. The collected data was computerised and analysed using appropriate
Table 2. Distribution of clinical diseases

\begin{tabular}{lrr}
\hline Disease at presentation & $\begin{array}{c}\text { Number } \\
(\mathbf{N}=\mathbf{1 9 0})\end{array}$ & $\begin{array}{c}\text { Percentage } \\
\text { (\%) }\end{array}$ \\
\hline RDS & 67 & 35.3 \\
MAS & 35 & 18.4 \\
Apnoea & 33 & 17.4 \\
Persistent pulmonary & 15 & 7.9 \\
hypertension of newborn & & \\
(PPHN) & & \\
Birth asphyxia & 11 & 5.8 \\
CNS related - Intracranial & 9 & 4.7 \\
haemorrhage and raised & & \\
ICP & & \\
Septicaemia & 8 & 4.2 \\
Pneumonia & 8 & 4.2 \\
CHD & 4 & 2.1 \\
\hline
\end{tabular}

statistical methods like Chi-square test, $\mathrm{t}$ - test, multivariate analysis, etc.

\section{RESULTS}

Of the 285 neonates needing mechanical ventilation during the study period, 190 cases were finally analysed, meeting the inclusion and exclusion criteria (Figure 1).

Majority of the neonates included were born outside KGP (93.2\%). The percentage of babies who got admitted within the first 24 hours of life was $63.2 \%$. Among the babies, $48.3 \%$ were preterm and $21.6 \%$ were very low birth weight (Table 1 ).

Overall mortality was 99 out of the 190 enrolled $(52 \%)$, of which $81(43 \%)$ died while receiving mechanical ventilation; the rest died after weaning off from the ventilator due to some other cause (e.g. aspiration, acute renal failure, sepsis with refractory shock). Among the ventilated babies, 91 (47.9\%) were successfully weaned off from the ventilator and discharged from the NICU (Figure 1).

As shown in Table 2 below, the most common indication for mechanical ventilation was Respiratory Distress Syndrome (RDS) (35.3\%), followed by Meconium Aspiration Syndrome (MAS) (18.4\%) and apnea (17.4\%). 
Table 3. Risk factors affecting survival of the mechanically ventilated neonates

\begin{tabular}{|c|c|c|c|c|c|c|c|}
\hline \multirow[t]{2}{*}{ Risk factor } & \multirow{2}{*}{$\begin{array}{c}\text { Number } \\
(\mathrm{N}= \\
190)\end{array}$} & \multirow{2}{*}{$\begin{array}{c}\text { Percentage } \\
(\%)\end{array}$} & \multicolumn{2}{|c|}{ Survival group } & \multicolumn{2}{|c|}{ Non survival group } & \multirow[t]{2}{*}{ p value } \\
\hline & & & $\begin{array}{c}\text { Number of } \\
\text { cases }\end{array}$ & $\begin{array}{c}\text { Percentage } \\
(\%)\end{array}$ & $\begin{array}{l}\text { Number } \\
\text { of cases }\end{array}$ & $\begin{array}{c}\text { Percentage } \\
(\%)\end{array}$ & \\
\hline \multicolumn{8}{|l|}{ Baseline characteristics } \\
\hline $\begin{array}{l}\text { Low Birth weight }(<1500 \\
\text { grams) }\end{array}$ & 41 & 21.6 & 12 & 29.3 & 29 & 70.7 & 0.007 \\
\hline Preterm $(\mathrm{GA}<32$ weeks $)$ & 32 & 16.8 & 9 & 28.1 & 23 & 71.9 & 0.014 \\
\hline Male gender & 124 & 65.3 & 60 & 48.4 & 64 & 51.6 & 0.852 \\
\hline \multicolumn{8}{|l|}{ Morbidity } \\
\hline Sepsis & 115 & 60.2 & 59 & 51.3 & 56 & 48.7 & 0.244 \\
\hline DIC & 46 & 24.2 & 17 & 37 & 29 & 63 & 0.088 \\
\hline Shock & 62 & 32.6 & 21 & 33.9 & 41 & 66.1 & 0.007 \\
\hline \multicolumn{8}{|c|}{ Mechanical ventilation related complications } \\
\hline $\begin{array}{l}\text { Ventilator Associated } \\
\text { Pneumonia }\end{array}$ & 40 & 21.1 & 18 & 45 & 22 & 55 & 0.680 \\
\hline $\begin{array}{l}\text { Endotracheal tube related } \\
\text { complications }\end{array}$ & 43 & 22.6 & 23 & 53.5 & 20 & 46.5 & 0.404 \\
\hline $\begin{array}{l}\text { Pulmonary } \\
\text { Haemorrhage }\end{array}$ & 25 & 13.6 & 1 & 4 & 24 & 96 & 0.000 \\
\hline Pneumothorax & 28 & 14.7 & 6 & 21.4 & 22 & 78.6 & 0.002 \\
\hline
\end{tabular}

High mortality was found in babies ventilated for Congenital Heart Disease (CHD) (100\%), sepsis (87.5\%), Persistent Pulmonary (PPHN) (60\%) and MAS (50\%). Table 3 shows that $21.6 \%$ babies were VLBW, with a mortality rate of $70.7 \%$, while the mortality was $47 \%$ in babies who weren't VLBW (statistically significant $\mathrm{p}=0.007$ ). Similarly, mortality was higher in babies of gestation $<32$ weeks $(\mathrm{p}=0.014)$. As shown in table 3 below, related morbidities like shock, ventilation associated complications like pulmonary haemorrhage and pneumothorax contributed significantly to adverse outcome ( $\mathrm{p}$ values 0.007 , 0.000 and 0.002 respectively).

In multiple regression analysis, factors such as birth weight $<1500$ grams, complications such as circulatory disturbances, pneumothorax, pulmonary haemorrhage and higher initial $\mathrm{FiO} 2$ requirement were found to be independent risk factors for mortality in the mechanically ventilated neonate (Table 4).

Table 3. Multiple Logistic Regression Analysis of the risk factors contributing to mortality

\begin{tabular}{|lrrrrrr|} 
Variables & B & S.E. & P value & OR & \multicolumn{2}{c}{ 95\% C.L. for OR } \\
\cline { 5 - 7 } & & & & \multicolumn{2}{c}{ Lower } & Upper \\
\hline Circulatory disturbances & 1.024 & 0.367 & 0.005 & 2.784 & 1.356 & 5.713 \\
Pneumothorax & 1.322 & 0.536 & 0.014 & 3.750 & 1.313 & 10.711 \\
Pulmonary Haemorrhage & 3.353 & 1.056 & 0.001 & 28.596 & 3.609 & 226.552 \\
Birth weight $<1500$ grams & 1.255 & 0.452 & 0.005 & 3.509 & 1.447 & 8.508 \\
Initial $\mathrm{FiO}_{2}$ & 2.036 & 0.762 & 0.008 & 7.659 & 1.719 & 34.125 \\
\hline
\end{tabular}




\section{DISCUSSION}

The use of mechanical ventilation is an integral part of any nursery catering to sick neonates in both developed and developing countries. However, even today, mechanically ventilated neonates have a high fatality reported all over the world, ${ }^{5-7}$ the fatality being higher in the tertiary referral neonatal units receiving most cases as out born neonates. ${ }^{8}$ Results of the present study are discussed below along with comparison with other studies.

Various studies reported 3.5 to 13 percent of newborns who were mechanically ventilated from all NICU admissions, depending upon the centre, drainage area, cost, man power and infrastructure. ${ }^{4,9}$ The percentage is higher in this study because our centre caters to more out born neonates who need tertiary care in NICU and referred from the city and rural areas adjoining. In this study, $17 \%$ neonates were of less than 32 weeks of gestation, $31 \%$ were between 32 to 36 weeks as per expanded new Ballard score applied to find out gestational age. Other Indian studies reported a similar cohort with 16 to $17 \%$ for $<32$ weeks gestation, $30 \%$ to $40 \%$ for 32 to 37 respectively. ${ }^{10,11}$ Preterm babies suffer from RDS, apnea, sepsis, pneumonia, pulmonary haemorrhage etc. and they need mechanical ventilation more than term neonates. ${ }^{12}$

Overall mortality in this study was $52.1 \%$. Among them, $43 \%$ had died while on ventilator and $9 \%$ died after successful weaning from ventilator due to other causes such as aspiration, sepsis with refractory shock, ARF. $47.9 \%$ babies were successfully weaned from ventilator and discharged. A study conducted in Surat in 2009 reported similar mortality of $54 \%$ among which $52 \%$ expired while on ventilator and $2 \%$ after successful weaning from ventilator due to other causes. ${ }^{10}$

RDS, MAS and apnea were common indications for mechanical ventilation in our study. Similar results were seen in the studies conducted in Nepal (indications - birth asphyxia, sepsis and MAS), ${ }^{13}$ and in Karnataka (indications- birth asphyxia, RDS, sepsis). ${ }^{14}$
On comparing complications in survival and nonsurvival group, $p$ value was statistically significant with complications such as circulatory disturbances, pneumothorax and pulmonary haemorrhage, for contributing to adverse outcome. A study conducted in Puducherry reported similar mortality pattern in relation to complications. They found that, the highest mortality was seen with pneumothorax and pulmonary haemorrhage in $100 \%$ and $94 \%$ respectively followed by $83.4 \%$ in DIC, $65.6 \%$ in pneumonia / sepsis and $43 \%$ in shock. ${ }^{15}$

On multiple regression analysis, risk factors like very low birth weight, higher initial $\mathrm{FiO} 2$ and complications such as pneumothorax, pulmonary haemorrhage and circulatory disturbances were found to be significant independent predictors of fatality in the mechanically ventilated neonates. A study conducted in Kerala also reported pulmonary haemorrhage and DIC as the independent risk factors for the fatality. ${ }^{16}$

From the present study, risk factors mentioned below were identified as predictors of adverse outcome in the mechanically ventilated neonates, whose knowledge can help deduce prognosis at the outset, or help strengthen efforts by earmarking high-risk cases. The major risk factors and significant predictors for high mortality that we noted were VLBW and pre-terms less than 32 weeks. Complications like pneumothorax and pulmonary haemorrhages were the major significant predictors of deaths in the mechanically ventilated neonates.

Although our study has tried to look into various factors which required ventilation among neonates, and significant factors which predicted mortality in ventilated NICU babies, there are various limitations in our research. Some of the limitations of our study include a small sample size, limited to a single centre, which caters to a major population of referrals for tertiary care. Hence the extrapolation of data has been difficult and our findings may not be generalised to the entire population. However, we recommend further more comprehensive, multi-centric study in the future to divulge further into the subject. 


\section{CONCLUSIONS}

The commonest indications for mechanical ventilation in neonates were RDS followed by MAS and apnea in our study. The mortality was significantly high amongst VLBW neonates and preterm neonates with $\leq 32$ weeks. Co-morbidities like circulatory disturbance, and ventilator associated complications like pneumothorax and pulmonary haemorrhage contributed to the adverse outcome.

\section{REFERENCES}

1. Census Commissioner of India. Sample Registration System Statistical Report 2017. [Internet] [Updated 12 May, 2020; Cited 2 June, 2020]. Available from: http://censusindia.gov.in/vital_statistics/SRS_Reports_2017.html

2. Upadhyay RP, Chinnakali P, Odukoya O, Yadav K, Sinha S, Rizwan SA, et al. High Neonatal Mortality Rates in Rural India: What Options to Explore?.ISRN Pediatr. 2012;2012:968921. DOI:10.5402/2012/968921.

3. Rammohan A, Iqbal K, Awofeso N. Reducing Neonatal Mortality in India: Critical Role of Access to Emergency Obstetric Care. PLoS ONE. 2013;8(3):e57244. DOI: 10.1371/journal.pone.0057244.

4. Iqbal Q, Younus MM, Ahmed A, Ahmed I, Iqbal J, Charoo BA, et al. Neonatal mechanical ventilation: Indications and outcome. Indian J Crit Care Med. 2015;19(9):523-7. DOI: 10.4103/0972-5229.164800.

5. Nangia S, Saili A, Dutta AK, Gaur V, Singh M, Seth A at al. Neonatal mechanical ventilation-experience at a level II care centre. Indian J Pediatr. 1998;65(2):291-6. DOI: 10.1007/BF02752306.

6. Singh M, Deorari AK, Paul VK, Mittal M, Shanker S, Munshi U, et al. Three year experience with neonatal ventilation from a tertiary care hospital in Delhi. Indian Pediatr.1993;30:783-9. PMID: 8132260

7. Mathur NC, Kumar S, Prasanna AL, Sahu UK, Kapoor R, Roy S et al. Intermittent positive pressure ventilation in a neonatal intensive care unit: Hyderabad experience. Indian Pediatr. 1998;35:349-53. PMID: 9770890

8. Mathur NB, Garg P, Mishra TK. Predictors of Fatality in Neonates Requiring Mechanical Ventilation. Indian Pediatr. 2005;42(7):645-51. PMID: 16085965.

9. Kushwaha AS. Newborn care in India: a crying need of the hour. Med J Armed Forces India. 2011;67(2):104-9. DOI: $10.1016 / \mathrm{S} 0377-1237(11) 60002-6$.

10. Trivedi SS, Chudasama RK, Shrivastava A. Study of Early Predictors of Fatality in Mechanically Ventilated Neonates in NICU. Online J Health Allied Scs. 2009;8(3):9.

11. Dutt RD, Dutt C, Ambey R. Neonatal Mechanical Ventilation-Early Experiences in central India. Int J Med Res Rev. 2014;2(4):319-23. DOI: https://doi.org/10.17511/ijmrr.2014.i04.10.

12. Bhakta KY, Respiratory distress syndrome. In: Cloherty JP (ed.) Manual of Neonatal Care, 7th edition. New Delhi: Wolters Kluwer (India) Pvt Ltd; 2012:408-409.

13. Shah BK, Shah GS, Mishra OP. Mechanical Ventilation in Neonates: Experience at a Tertiary Care Centre in Eastern Nepal. JAMMR. 2014;5(1):75-80. DOI: https://doi.org/10.9734/BJMMR/2015/8207.

14. Patil BM, Sandeep VH, Harish G, Patil VM, Vijayanath V. Outcome of neonates on mechanical ventilation graduating from NICU. IJPBS. 2013;3(2):50-6.

15. Anantharaj A, Bhat BV. Outcome of neonates requiring assisted ventilation. Turk J Pediatr. 2011;53(5):547-53. PMID: 22272457.

16. Nayanaprabha PC, George RT, Francis F. Profile and outcome of neonates requiring ventilation: The Kerala experience. Curr Pediatr Res. 2014;18(2):57-62. Corpus ID: 55569305 